\title{
A Report on International Conference on "Advances in Sustainable Agriculture: Bioresources, Biotechnology and Bioeconomy"
}

An International Conference on "Advances in Sustainable Agriculture: Bioresources, Biotechnology and Bioeconomy" was organised on November 29 and 30, 2019 at Bhopal, Madhya Pradesh. The International Conference was jointly organized by the Mansarovar Global University, Bhopal and the PHSS Foundation for Science \& Society, Lucknow.

The inaugural function was presided over by the Chief Guest, Dr Manju Sharma, NASI-DST Women Distinguished Scientist Chair and former Secretary, Department of Biotechnology, Government of India. Mr. Gaurav Tiwari, Pro-Chancellor of Mansarovar Global University welcomed the dignitaries and participants. In his welcome address he said that the Indian scientific community has great responsibility in ensuring the food and nutritional security of the country and at the same time contributing to the welfare of the farming community. Poverty and hunger need to be alleviated at war footing. Welcoming the delegates, Professor Arun Kumar Pandey, Vice-Chancellor, Mansarovar Global University, emphasized that India has robust farming communities and traditions, but they need technological inputs for higher crop yield, control of pests and pathogens, post-harvest storage, transportation and marketing. Molecular and biotechnological tools should also be pressed into service for achieving crop yields comparable to developed countries. Wise use of water and reduced dependence on pesticides are also important for sustainable agriculture.

In the inaugural session, Prof. R.P. Singh, Secretary General of PHSS Foundation highlighted the objectives and functioning of the foundation and announced the Conferment of Lifetime Achievement Award on Dr. Manju Sharma. Five other scientists received awards for excellence in their fields of scientific activity. Prof. P.K. Seth, President, PHSS Foundation gave a brief background of the Young Scientist Conclave and emphasised the need for utilizing the biotechnological techniques for crop improvement.

Dr Manju Sharma delivered the inaugural address and acceptance speech for Lifetime Achievement Award. She said that for Indian Agriculture to be sustainable we need to take care of soil, water, biodiversity and quality of human life. She threw light on the recent trends in agriculture and emphasised that there is a need for enriching the rural economy and enhance farmer's income. The problem of hunger and malnutrition should be solved through crop diversification, improved varieties and environment-friendly methods of cultivation. Farmers deserve help in profitable marketing of their produce. Dr Sharma also stated that greater involvement of women in science is essential, as women are more sensitive to environmental and human needs.

Invited lectures were delivered by Prof. Marcio J. Pocas-Fonseca (University of Brasilia, Brazil), Prof. N. Raghuram (GGS Indraprashtha University, New Delhi), Dr R.D. Tripathi (CSIR-National Botanical Research Institute, Lucknow), Prof. Naveen Kumar Arora (Babasaheb Bhimrao Ambedkar University, Lucknow), Prof. Renu Deswal (University of Delhi), Prof. S.M. Paul Khurana (Amity University, Haryana), Dr M.K. Tripathi (ICARCIAE, Bhopal), Dr Girish Mishra (University of Delhi), Prof. V.N. Pandey (DDU Gorakhpur University, Gorakhpur), Prof. C. Rajasekaran (Vellore Institute of Technology, Vellore). PHSS 


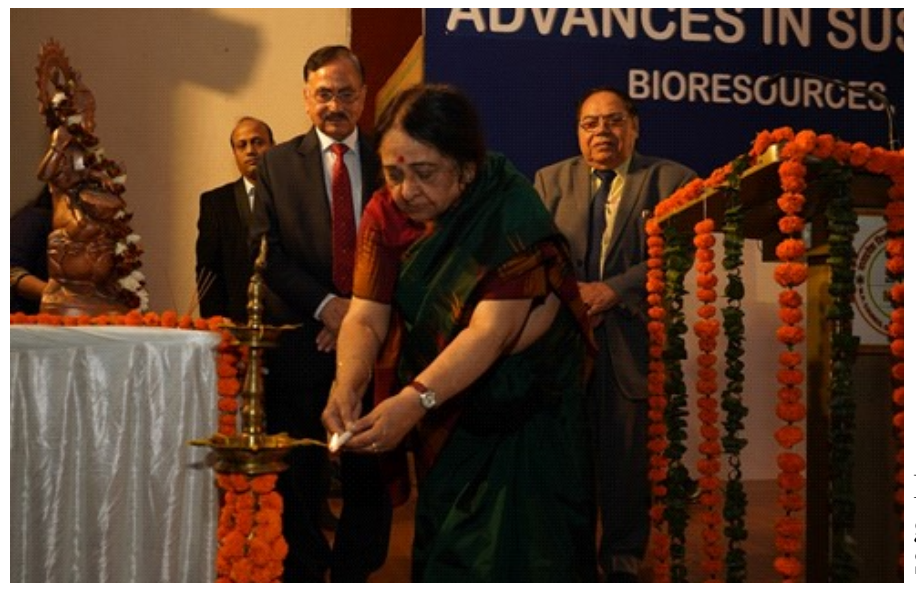

Lighting the lamp during the inaugural ceremony by Dr Manju Sharma

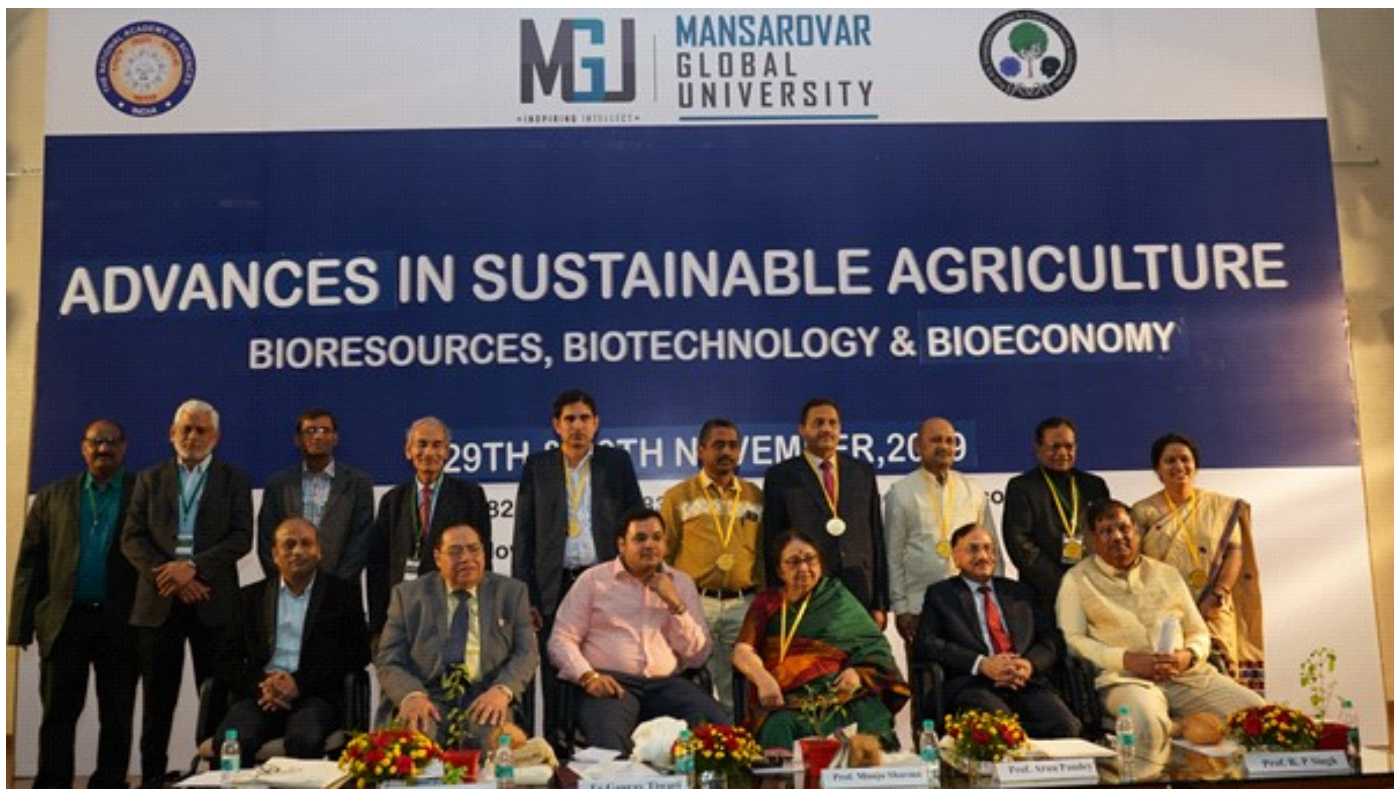

Dignitaries on the dais along with awardees and Office bearers

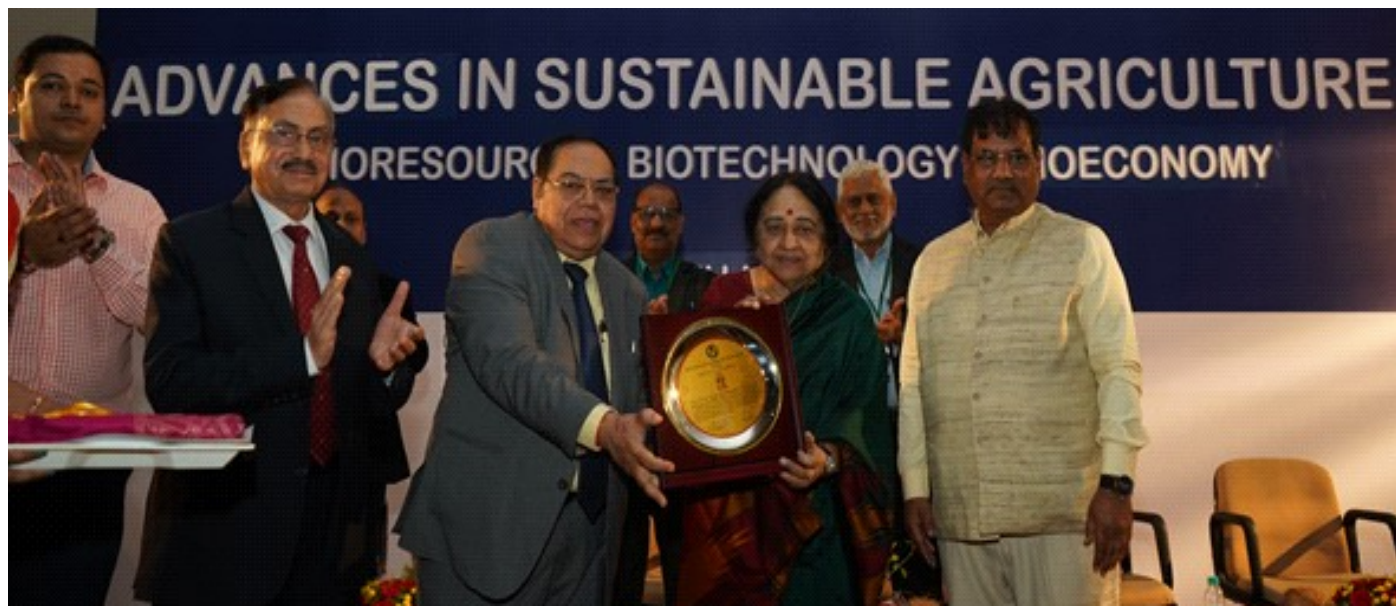

Lifetime Achievement Award bestowed upon Prof. (Dr) Manju Sharma 


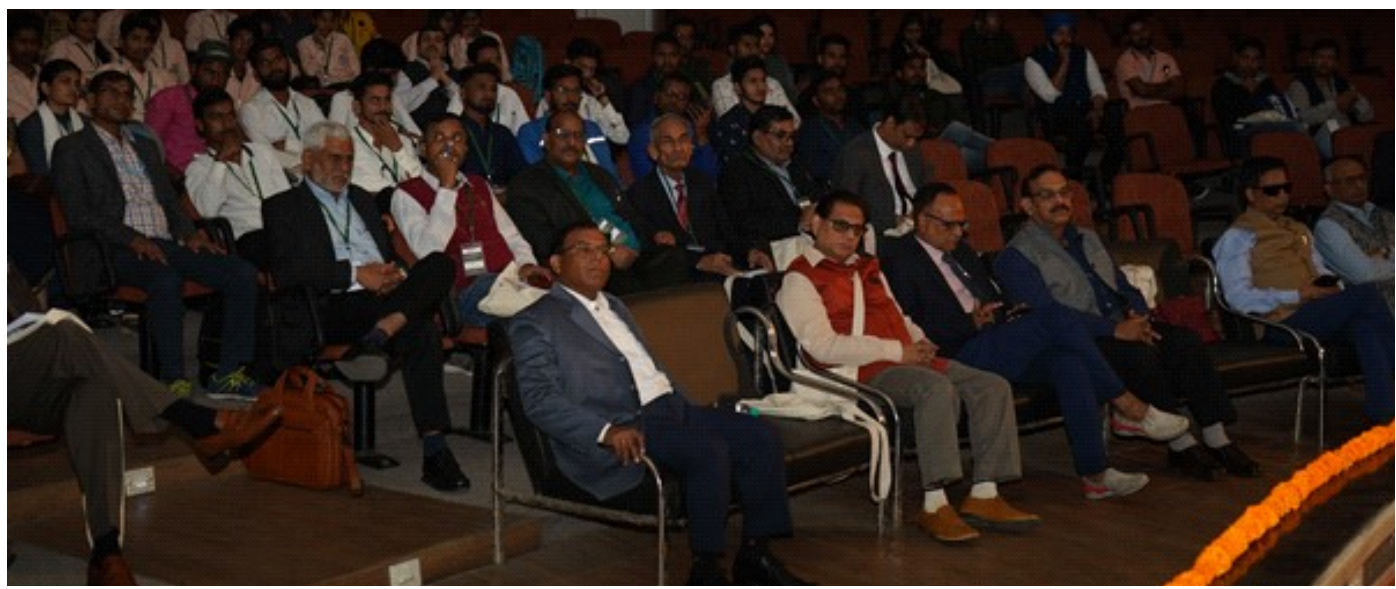

Invited speakers and delegates of International Conference

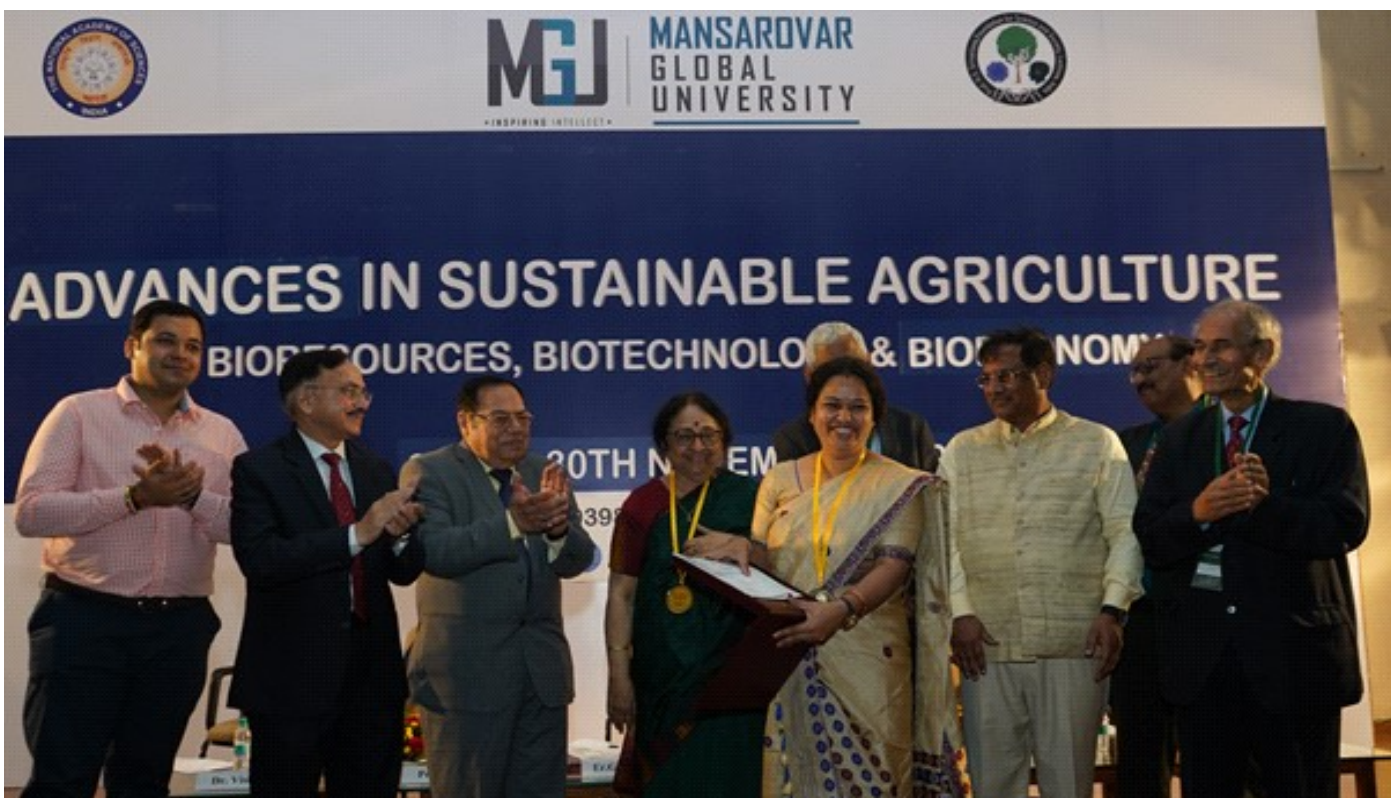

Confering PHSS Young Women Scientist Award to Dr P. Saikia

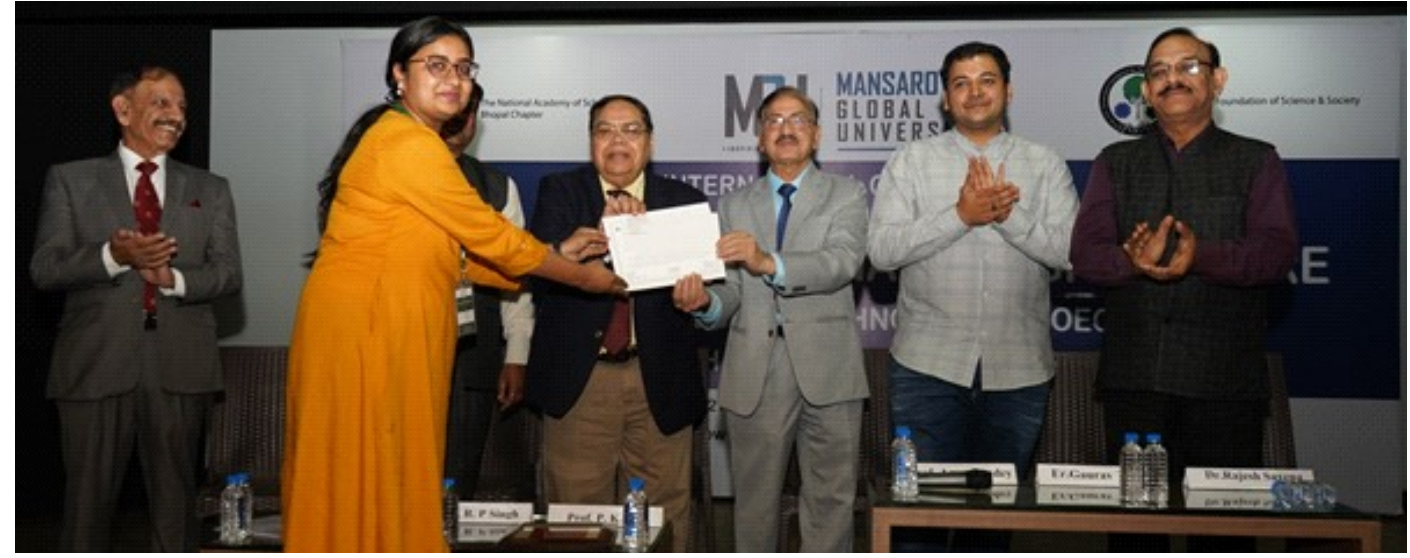

Prof. (Dr) A.K. Pandey giving PHSS-MGU-Springer award certificate to Shruti Kasana 
Foundation Award lectures were delivered by Prof. R.C. Chaudhary (PRDF, Gorakhpur) and Dr Purabi Saikia (Central University of Jharkhand, Ranchi). Dr Ulrich Berk from Germany presented scientific evidence on how homo organic farming (Agnihotra') helped in improving air quality and in enhancing crop yields through improved soil quality and optimal water use.

The major thematic areas covered during the conference were: 1. Bioresources and Biodiversity, 2. Plant Tissue Culture and Transgenic Technology, 3. Plants and Biotic stresses/ Plant-Microbe Interactions, 4. Plant Genetics and Breeding, 5. Agro-product processing and entrepreneurship and 6. Impact of Climate Change on Agriculture.

A Young Scientist Conclave was organised on the second day of the conference. Dr P.K. Singh (CSIR-National Botanical Research Institute, Lucknow) delivered lead lecture and highlighted the work being done on developing cotton varieties resistant to white fly that cause viral diseases. His lecture was followed by presentations of the young scientists on molecular and biotechnological aspects of crop improvement which have the potential to revolutionize agriculture in India. Besides oral presentations, poster session was also organised. Many of the presentations generated lively discussions.

At the valedictory function on second day of the conference, Mr. Gaurav Tiwari said that agriculture is the backbone of Indian economy and over $50 \%$ of our people depend on it for their livelihood. He called upon the scientists to combine traditional practices and modern technology for developing crops that would help achieve higher productivity. In his valedictory remarks, Prof. P.K. Seth suggested that India, being one of the richest countries of the world in biodiversity, is uniquely positioned to harness the potential of bio-based economy. There is an urgent need to take appropriate measures to make India a bioresource-based economy that would help achieve economic and environmental sustainability in both rural and urban areas. Prof. Arun Pandey emphasized that application of biotechnology would be crucial for crop improvement in India. Food that we produce should be more nutritious and farmers should earn more for their produce. There should be active participation of growers, distributors, retailers, consumers and waste managers who play a major role in ensuring a sustainable agricultural system.

A total of 130 delegates from across the country and abroad participated. The conference provided an opportunity to the participants to exchange their views and share their ideas for promoting sustainable use of bioresources, use of biotechnology in crop improvement and bioeconomy. This Conference was sponsored by the National Academy of Sciences, India and NASI (Bhopal Chapter). The certificate to the winners of young scientist award were distributed by the dignitaries on the dais.

Arun K. Pandey

Mansarovar Global University Bhopal, Madhya Pradesh, India E-mail:arunpandey79@gmail.com 